\title{
Towards a Common Transnational Education Framework: Peculiarities in China Matter
}

\author{
Mingyan $\mathrm{Hu}^{*^{\mathrm{a}}}$ and Linda-Dianne Willis ${ }^{\mathrm{b}}$
}

\begin{abstract}
Knight has proposed a common transnational education framework for use within and among countries. How this framework may be applied in particular contexts such as those of host countries like China remains unclear. The purpose of this article is to examine the literature to explore the framework to ascertain the extent of its utility in China in terms of application and research. The investigation highlights two areas for considerations by researchers and data collectors who may use the framework. The article concludes that understanding the peculiarities of transnational education in host countries, plays a critical role in addressing the challenges associated with the development and application of a common framework and ultimately a robust international protocol for data collection of transnational education.
\end{abstract}

Key words: Transnational education (TNE), common framework, China, Chinese-Foreign Cooperation in Running Schools (CFCRS)

\section{Introduction}

During the last four decades, the scope and scale of higher education moving across borders, or transnational education (TNE), has experienced unprecedented growth, resulting in dramatic changes around the world. The result of this rapid growth has meant that data collection and analysis on TNE globally has been neither systematic nor consistent. Research and practice in TNE have therefore suffered from a lack of comparable data worldwide. To begin to address this situation, Knight (2016) has proposed a TNE framework with a common set of categories and definitions for use by researchers and data collectors. It is unclear however, how this framework may be applied in different contexts of sending and host countries.

\footnotetext{
a *Corresponding author. School of Humanities, Languages, and Social Sciences, Griffith University, Brisbane, QLD, 4111 Australia, mingyan.hu@griffithuni.edu.au

b Faculty of Humanities and Social Sciences, School of Education, University of Queensland, Brisbane, QLD, 4072 Australia, I.willis@uq.edu.au
} 
Using the literature and related documents, for example, research books, journal articles, reports from organizations, government public policy texts, and websites, this article sheds light on the utility of the framework by adopting the perspective of one host country - China. The article asks the question: What should be considered when applying Knight's common TNE framework in host countries? Findings from this investigation contribute to a better understanding of TNE in China, and enhance understanding about the potential utility of Knight's common TNE framework for use in the context of other host countries. At the same time, the article highlights what needs to be considered in applying Knight's framework to facilitate effective data collection within and among countries.

This article first provides a background on global education mobility and Knight's (2016) common TNE framework. Next, two different perspectives on TNE are illustrated and compared, and the decision to focus on the perspective of a host country is elucidated. The article then reviews prominent characteristics of TNE in China and discusses three different types of TNE operations. A critical analysis on the relationship between TNE in China and the proposed common framework is subsequently presented. From the examination of China's case, the article concludes that in order to apply a common framework that improves data quality in research and practice in TNE, it is necessary to understand the peculiarities of each host country.

\section{Background: Global education mobility and a common TNE framework}

The international higher education sector has been growing rapidly since the 1980s, encouraging and facilitating students, academics, and education programs and institutions to move around the world (Altbach and Knight, 2007; Rumbley, Altbach, and Reisberg, 2012). Traditional student mobility through studying abroad is gradually giving sway to a new landscape where various types of educational providers now send their programs to students' own countries and establish campuses across borders (Cai, Hölttä, and Lindholm, 2013). These new forms of global education mobility have empowered students with various cost-efficient options and pathways to gain a foreign qualification or credit. Rather than travelling abroad, students can reduce the cost of their education by choosing to study a foreign program or course, either full- or part-time, in their own country. Their study can also take various modes from online or distance education, to learning in physical locations such as International Branch Campuses (IBCS), or in joint or twinning programs at a local partner institution of the foreign awarding provider. 
Under these arrangements, various terms such as offshore, transnational, cross-border and borderless education have emerged and are often used interchangeably to describe the situation where students and their foreign awarding institutions are not located in the same country or region. For the purpose of this article, the authors follow Knight's (2016) lead in adopting the term, transnational education or TNE, to conceptualize "the mobility of an education program or higher education institution (HEI)/provider" (p.36).

There is little doubt that TNE has grown exponentially in recent years. Numbers on various TNE operations speak for this trend. For example, by June 2016, there were 232 IBCs in operation globally with 25 new IBCs under development (Cross-Border Education Research Team [C-BERT], 2016). In 2014/2015, 99 out of 134 United Kingdom (UK) higher education institutions (HEIs) had together enrolled a total of 665,995 TNE students (HEGlobal, 2016). Early players in the TNE field were mostly from Anglophone countries (e.g. UK, United States of America [USA], Australia, New Zealand, Canada); but in the last few years, non-Anglophone countries have also joined this global trend (Wilkins and Urbanovič, 2014). These include International Education Hubs in the Middle East (Qatar, United Arab Emirates), Southeast Asia (Hong Kong, Malaysia, Singapore) and Africa (Botswana) (Knight, 2014).

Given this dynamic and unprecedented development, systematic approaches to conceptualizing, tracking and monitoring various TNE activities have not been possible. In the absence of a common framework for categorizing and defining these activities, sending and host countries have not yet reached a collective understanding of what TNE entails. This absence has given rise to inconsistent data collection, limiting the research possible, and making data comparisons difficult. According to Knight and McNamara (2015), this situation is exacerbated in host countries where TNE data collection is sporadic and unsystematic. As well, more research has been conducted in sending than host countries. Without quality data to inform policy and practice in the TNE field, relevant governments and agencies, especially those from host countries, face serious challenges in developing regulation and quality assurance safeguards. Worldwide, this absence has intensified the difficulties in monitoring and assessing the scope, extent, value and impact of increasing and changing TNE activities.

In an attempt to overcome such challenges, Knight (2016) has proposed a TNE framework with a common set of categories and definitions for use by researchers and data collectors within and among countries. According to Knight, this common framework seeks to be "robust enough to distinguish different modes of TNE 
but flexible enough to be used by a wide range of sending and host institutions/countries across the world all of whom are at different stages of TNE provision" (р. 37). Knight's framework is intended to provide an analytical tool to better understand the TNE phenomenon. The principles that underpin the framework seek to organize TNE activities so that similarities and distinctions among these are more readily discernible. For example, TNE operations are categorized as collaborative between local/host and foreign/sending providers or independent with education provided solely by the foreign sending $\mathrm{HEI} /$ provider. More specifically, TNE activities in the collaborative category entail four modes: twinning programs, joint/double/multiple degree programs, co-founded or co-developed universities, and locally supported distance education programs. In the independent category, TNE operations include three modes: branch campus, franchise university, and distance education. These seven modes are presented in a simplified version of Knight's (2016) framework in Table 1.

Table 1. Simplified version of Knight's common TNE framework

\begin{tabular}{|c|c|c|}
\hline \multicolumn{2}{|l|}{ TNE Mode } & \multirow{2}{*}{$\begin{array}{l}\text { Definition } \\
\text { A foreign sending HEI offers academic program(s) through a host country HEI. } \\
\text { Foreign sending HEI provides curriculum and awards qualifications. }\end{array}$} \\
\hline $\begin{array}{l}\text { Collaborative } \\
\text { TNE provision }\end{array}$ & Twinning programs & \\
\hline & $\begin{array}{l}\text { Joint/double/multiple } \\
\text { degree programs }\end{array}$ & $\begin{array}{l}\text { The program curriculum is jointly designed, delivered, and monitored by all } \\
\text { local and foreign partners. Different combinations of qualification provided } \\
\text { depending on host country regulations. }\end{array}$ \\
\hline & $\begin{array}{l}\text { Cofounded/develope } \\
\text { d universities }\end{array}$ & $\begin{array}{l}\text { An } \mathrm{HEI} \text { is established in host country in collaboration with foreign sending } \\
\mathrm{HEIs.} \mathrm{The} \mathrm{academic} \mathrm{programs} \mathrm{are} \mathrm{offered} \mathrm{through} \mathrm{twinning} \mathrm{or} \\
\text { joint/double/multiple degree arrangements. Local host HEIs also develop } \\
\text { academic programs independent of foreign partners. }\end{array}$ \\
\hline & $\begin{array}{l}\text { Locally supported } \\
\text { distance education } \\
\text { programs }\end{array}$ & $\begin{array}{l}\text { A foreign distance education } \mathrm{HEl} / \text { provider offers programs with academic } \\
\text { support for students available from local entity. Qualification and curriculum } \\
\text { offered by foreign distance education provider. }\end{array}$ \\
\hline \multirow[t]{3}{*}{$\begin{array}{l}\text { Independent } \\
\text { (foreign) TNE } \\
\text { provision }\end{array}$} & Branch campus & $\begin{array}{l}\text { A foreign sending } \mathrm{HEI} \text { offers academic programs through their own satellite } \\
\text { campus located in host counry. Qualification and curriculum offered by foreign } \\
\text { sending HEI. }\end{array}$ \\
\hline & Franchise university & $\begin{array}{l}\text { A private independent } \mathrm{HEI} / \text { provider offers a series of franchised academic } \\
\text { programs from different foreign sending } \mathrm{HEI} / \text { providers. Qualifcation and } \\
\text { curriculum offered by foreign sending } \mathrm{HEIs.}\end{array}$ \\
\hline & Distance education & $\begin{array}{l}\text { Foreign sending distance education provider offers academic programs } \\
\text { directly to host country students. No local academic support available. } \\
\text { Qualification, curriculum, and quality assurance offered by foreign sending } \\
\text { HEI. }\end{array}$ \\
\hline
\end{tabular}

Source. Knight (2016, P. 44).

Note. TNE = transnational education; $\mathrm{HEI}=$ higher education institution

Knight (2016) acknowledges that while the need for clarity and consistency among terms underpins the framework's development, potential tensions created by the use of generic over specific terminology may have 
compromised nuanced definitions. For example, she points out that risks to the framework occur when host countries use "their own terminology to align with national policies/regulations and purposes of TNE" and where "national data collection systems on TNE programs and enrolment are scarce" (p.46). These considerations are particularly relevant when it comes to TNE activities in China where local terms such as Chinese-Foreign Cooperation in Running Schools (CFCRS) are used to comply with specific national policies/regulations and data collection systems. This article thus proposes to use the literature and related documents to examine the utility of Knight's framework from the perspective of China as a host country.

\section{Perspectives in TNE: Hosts versus providers}

Commonly, the word 'perspective' means a particular attitude toward or way of viewing things (Oxford Dictionary of English, 2010). It also refers to a particular lens or form of analysis of a phenomenon that reflects its true relations and relative importance (Merriam-Webster Dictionary and Thesaurus, 2014). In relation to TNE, perspective matters. This is because "rationales, impacts, policies and regulations can differ significantly depending on whether it is a sending or host country" (Wilkins and Huisman, 2012, as cited in Knight, 2016, p.35). As most research on TNE has been conducted from a sending/provider country's perspective, what is happening in host countries is less well known. Knight and McNamara (2015) advocate for a shift in focus to host countries to better understand and coordinate views and opionions in research and practice.

Such a shift in focus has important implications for research, especially for countries like China now transitioning from a traditional host role to an emerging provider profile. If the situation continues where no clear distinction is made between sending and host countries, TNE data collection and analysis will be inconsistent and chaotic. This is because TNE activities and concepts can mean different things and require different data sets depending on a host or a provider perspective. For example, in China, the concept of 'students in TNE programs' could have at least two different meanings: a) students who are studying foreign education programs hosted by Chinese HEls in China; or b) students who are studying Chinese education programs hosted by foreign HEls abroad. The first meaning refers to 'Chinese students studying in TNE operations in China' and so relates to China as a host country. This perspective is best described as 'TNE in China'. The second meaning refers to 'students of other nationalities studying in China's TNE operations in students' own countries/regions' and so relates to China as a provider country. This perspective is best 
described as 'China's TNE'. The next section looks at these two perspectives in detail to explain why taking a host country's perspective to explore the relative utility of Knight's framework is important.

\section{TNE in China: A host perspective}

Since the mid-1980s, China has encouraged foreign HEls/providers to establish programs and institutions in collaboration with Chinese HEls. The purpose has been to introduce advanced foreign education resources to enhance Chinese HEIs' academic capacity and global competitiveness (Huang, 2007, 2008; Zha, 2012). Distinct from most Anglophone TNE sending countries, this non-revenue-driven national rationale has given rise to China's rigid control over foreign HEIs/providers generating profits from TNE activities. Although more recently China has allowed foreign TNE providers to make reasonable profits, tuition standards of TNE programs hosted in most public Chinese HEls are still strictly controlled by China's central and provincial/municipality governments (Mok and Han, 2016b). To monitor and regulate various TNE activities, China's Ministry of Education (MOE) (2003) established the Division of Supervision on Education Involved in Foreign Activities and its special website (www.jsj.edu.cn) as a public information platform. In 2010, it launched a national supervision mechanism through a subordinate website namely the Chinese-Foreign Cooperation in Running Schools Supervision Workstation (www.crs.jsj.edu.cn). From then, basic information of TNE programs and institutions officially approved and cooperatively run by Chinese and their foreign partner HEls/providers in China have been publicly accessible on this Supervision Workstation website. According to this platform, by the end of 2015, there were: 590 Chinese HEls collaborating with over 400 foreign HEls/providers in running 2,376 cooperative programs and institutions; and approximately 55,000 Chinese students enrolled on campus and another 1.5 million students who had graduated (China Education Daily, 2016). Nearly half of the 2,376 Chinese-foreign cooperative operations were at undergraduate level or above with official approval from the MOE (Mok and Han, 2016a). These included:

- Eight Chinese-foreign cooperation universities (which are not affiliated to Chinese HEIs, e.g. Ningbo Nottingham University, Xi'an Jiangtong-Liverpool University, Shanghai New York University, Kunshan Duke University)

- 52 Chinese-foreign cooperation second-tiered colleges (which are affiliated to Chinese HEIs, e.g. Chinese-French Institute at Renmin University of China, Sydney Institute of Languages and Commerce at Shanghai University, Chinese-Danish College at University of Chinese Academy of Sciences), and 
- 1,052 Chinese-foreign cooperation programs (which are affiliated to Chinese HEls, e.g. Bachelor's Program of Science in Accounting jointly run by Wenzhou University, China and Kean University, USA).

Given the large scale of TNE in China and its impact on education, policy, economy, and society, understanding the peculiarities of TNE in China has conceptual and practical implications for the utility of Knight's (2016) common TNE framework.

\section{China's TNE: A provider perspective}

In contrast, China's TNE presents an outward trajectory of exporting Chinese higher education for the purpose of disseminating Chinese culture and cultivating a favourable international environment for China's socio-economic development (Huang, 2007). This outward mobility of Chinese higher education is still in its nascent stage compared with the above-mentioned proliferation of TNE operations in China. Since 2004, Chinese HEls have been delivering Chinese language and culture programs globally through their Confucius Institutions and Classrooms in partnership with local tertiary institutions, colleges and high schools. By 2015, 500 Confucius Institutions and over 1,000 Confucius Classrooms had been established across 134 countries (China Education Daily, 2016). In addition, by 2014, Chinese HEls had set up 93 TNE programs and three TNE institutions overseas, and by 2015, these figures had increased to 98 and four respectively (MOE, 2014, 2016). The four TNE institutions overseas approved by the MOE were:

- Soochow University in Laos founded in July 2011, offering undergraduate programs of International Economy and Trade, International Finance, Chinese Language, and Computer Science and Technology

- Bangkok Business School set up and jointly run by Yunnan University of Finance and Economics and Thailand's Rangsit University in December 2013, providing six undergraduate and graduate programs on economics and administration

- Xiamen University Malaysia Campus founded in July 2014, offering 12 undergraduate programs such as Chinese studies, Traditional Chinese Medicine, Science in Marine Biotechnology, New Energy Science and Engineering, and International Business, and

- Beijing Language and Culture University Tokyo College founded in April 2015 offering degrees mostly on language and culture. 
As noted by the MOE (2014), China's TNE programs and institutions in 14 countries cluster in the Southeast Asian region, providing education predominantly in traditionally prestigious disciplines such as Chinese language, culture, medicine and martial arts. Despite these four MOE-approved TNE institutions, the establishment of several other TNE institutions were approved by provincial/municipality governments. A typical case is Tongji University Overseas Campus in Florence, Italy, which was founded in March 2014 with support from Shanghai Municipality and Florence Municipality, marking it as "the first offshore campus of a Chinese university in a Western Country" (Bellini, Pasquinelli, Rovai, and Tani, 2016, P.2).

Compared to TNE in China that is underpinned by national policies and regulations which have been in effect to date, there currently appears to be no specific national regulations to guide and supervise China's TNE operations overseas. This is because the Provisional Regulations on Chinese Higher Education Institutions Running Schools Overseas issued in February 2003 was repealed by the MOE (2015) in November 2015. Despite the possibility of China issuing a new regulation on China's TNE in the future, there appears to be no formal confirmation of such intent from China's official information outlets. Moreover, unlike TNE in China that is supported by a national database on the Supervision Workstation website, China's TNE has not been supported by a publicly accessible database. Current studies of China's TNE are therefore sporadic, being mostly based on information released from the MOE, Chinese HEIs/providers, and major education newspapers. Given this situation, taking the perspective of China as a host country (i.e. TNE in China) to explore the relative utility of Knight's (2016) framework presents a worthwhile exercise. To do this, it is first necessary to understand the main characteristics of TNE in China.

\section{Characteristics of TNE in China}

TNE in China has been developing for more than three decades, transitioning from a relatively laissez faire style in the 1990s to progressive standardization and legalization after 2003 (Wang, 2005). During this process, TNE in China has taken on unique characteristics which include: the cooperative principle, the two-tiered regulating system, and three different types of TNE operations.

\section{The cooperative principle}


TNE activities in China are required to be based on partnerships of cooperation or collaboration between foreign and Chinese HEls/providers. Cooperation refers to mutual investment from both Chinese and foreign HEIs in the areas of "capital, land-use right, objects, intellectual property rights, and other properties such as institutional brand, curriculum, management system, and so on" (Fang, 2012, P.6). This unique characteristic has resulted from dual restrictions, that is, China's commitments to international protocols and specific national policies and regulations.

One of the most important international protocols that China observes is the World Trade Organization's General Agreement on Trade and Services (GATS). However, China's commitments to the GATS are limited, restricting foreign HEls/providers in China in two ways. First, foreign educational institutions are not permitted to physically provide education services independently by establishing their offshore campuses and programs in China, unless they partner with local Chinese educational institutions (Cai, 2011). Second, qualified foreign individual educators may enter China to provide education services only when invited or employed by Chinese schools or other education institutions (Momii, 2002). What can be seen is that China's limited commitments to the GATS seek to rule out physically independent foreign education activities in China at the international level.

At the national level, there are three important official documents that govern TNE activities in China. The first is the Interim Provisions on Chinese-Foreign Cooperation in Running Schools ('the Interim Provisions') issued in Chinese language by the then National Education Committee (later the MOE) in 1995. The second is the Regulations of the People's Republic of China on Chinese-Foreign Cooperation in Running Schools ('the Regulations') issued in both Chinese and English languages by the State Council in 2003. The third is the Implementation Measures for the Regulations of the People's Republic of China on Chinese-Foreign Cooperation in Running Schools ('the Implementation Measures') issued by the MOE in 2004 which repealed and replaced the Interim Provisions. These official documents were introduced by China's central government to encourage China's educational institutions to cooperate with renowned foreign educational institutions - including those from regions such as Hong Kong, Macao and Taiwan - to introduce high-quality foreign educational resources for capacity building (Yang, 2008). The cooperative nature of TNE in China is explicitly embodied in the Chinese definition of Chinese-Foreign Cooperation in Running Schools (CFCRS) in Article 2 of the Interim Provisions, which in English is translated as: 
Foreign corporate, individuals, and related international organizations in cooperation with educational institutions or other social organizations with corporate status in China jointly establish education institutions in China, recruit Chinese citizens as major educational objectives, and undertake education and teaching activities. (McNamara, Knight, and Fernandez-Chung, 2013, P.13)

The cooperative nature of TNE in China is reinforced in the Regulations where CFCRS is defined as "the activities of the cooperation between foreign educational institutions and Chinese educational institutions in establishing educational institutions within the territory of China to provide education service mainly to Chinese citizens" (State Council of China, 2003, Article 2).

What is clear from these documents is that locally, CFCRS is used to denote officially approved TNE activities in China. Those foreign education activities in China that do not comply with the cooperative principle and/or operate without official approval are therefore not recognized officially as CFCRS or TNE in China. For example, Chinese and foreign HEls sign an agreement to recognize each other's credits in certain programs. The purpose is to open channels for student exchange programs, or to simply transfer or articulate Chinese students to study in the foreign $\mathrm{HEI}$ with advance standing. These foreign education activities in China do not comply with the cooperative principle, as they do not involve substantial investment of efforts and resources from the foreign $\mathrm{HEl}$ in program delivery and management. Of note is that these non-CFCRS activities in China tend to be adopted as early-stage internationalization strategies by Chinese HEls to build up international partnerships and networks. Despite the lack of precise data on these non-CFCRS activities, it is known that many CFCRS programs have benefited from and built upon some well-operated non-CFCRS activities (e.g. Bellini et al., 2016). Therefore, existing studies on TNE in China mainly refer to the officially-approved CFCRS programs and institutions that are collaboratively run by Chinese and their foreign partner HEls/providers.

\section{The two-tiered regulating system}

Under the Regulations and the Implementation Measures, a two-tiered regulating mechanism has been intended for TNE operations in China. Specifically, Chinese-foreign cooperation programs and institutions at undergraduate and above levels should be examined, approved, monitored and administrated by the education authorities of the central government, that is, the MOE. As well, Chinese-foreign cooperation programs and institutions at the sub-degree levels or offering vocational education, language and professional 
training, and non-academic qualifications, should be examined, approved, monitored and administrated by the education authorities of the provincial/municipality government where the Chinese education institution is located (State Council of China, 2003, Article 12). Provincial/municipality governments should then report their TNE operations to the MOE for examination and filing.

However, TNE in China is influenced by "a flexible relationship between government regulation and local practice" where many TNE operations approved locally have not always been reported to the MOE for examination and filing (Yang, 2008, P.276). This flexibility can also be seen in the application timings nationally and locally. Specifically, to establish Chinese-foreign cooperation programs and institutions that confer degrees, Chinese HEls have two fixed timings per year (i.e. March and September) to apply to the MOE. To establish Chinese foreign cooperation programs and institutions that do not confer degrees, Chinese HEls have various times throughout the year when they can apply to the municipality/provincial governments. What makes the situation more complex is that there appears to be no specific selection criteria used by the MOE or local governments to assess and approve these respective applications (He, 2016). This two-tiered regulating system has created the potential for loopholes and various disparate local practices in different provinces and municipalities. This situation could explain why the national database of TNE in China on the Supervision Workstation website mainly focuses on degree-awarding Chinese-foreign cooperation programs and institutions that are directly approved by the MOE, while those locally approved TNE activities operate less visibly. The absence of a robust regulating system aggravated by a comparatively underdeveloped national data collection system has rendered TNE in China a complex under-charted landscape.

\section{Three types of TNE operations in China}

As mentioned above, the MOE Supervision Workstation website publishes basic information of all MOE-approved and some locally-approved Chinese-foreign cooperation programs and institutions. Although TNE in China may be categorized as Chinese-foreign cooperation programs and Chinese-foreign cooperation institutions, due to specific national policies and regulations TNE activities in China actually entail three types as shown in Table 2. 
Table 2. Three types of TNE in China

\begin{tabular}{|c|c|c|}
\hline \multicolumn{2}{|l|}{ CFCRS mode } & \multirow[b]{2}{*}{$\begin{array}{l}\text { Description } \\
\text { A full-campus-scale university with legal person status established in China by } \\
\text { a host Chinese HEl and a foreign partner HEI/provider in cooperation, offering } \\
\text { education to Chinese students mainly through double/joint degree programs. } \\
\text { This cooperation university is not affiliated with the host Chinese HEl. There } \\
\text { are currently eight Chinese-foreign cooperation universities in China, inlcuding } \\
\text { Ningbo Nottingham University and Shanghai New York University. }\end{array}$} \\
\hline $\begin{array}{l}\text { CFCRS } \\
\text { institutions }\end{array}$ & $\begin{array}{l}\text { Chinese-foreign } \\
\text { cooperation universities }\end{array}$ & \\
\hline & $\begin{array}{l}\text { Chinese-foreign } \\
\text { cooperation second-tier } \\
\text { colleges }\end{array}$ & $\begin{array}{l}\text { A college/school without legal person status establihsed in China by a host } \\
\text { Chinese HEI and a foreign partner HEI/provider in cooperation, offering } \\
\text { education to Chinese students mainly through double/joint degree programs. } \\
\text { This cooperation college is affiliated with the host Chinese HEI, functioning as } \\
\text { a second-tier college under the host Chinese HEI. There are currently } 52 \\
\text { Chinese-foreign cooperation second-tier colleges in China, inlcuding the } \\
\text { Chinese-French Institute at Renmin University of China and the Sydney } \\
\text { Institute of Languages and Commerce at Shanghai University. }\end{array}$ \\
\hline $\begin{array}{l}\text { CFCRS } \\
\text { programs }\end{array}$ & $\begin{array}{l}\text { Chinese foreign } \\
\text { cooperation programs }\end{array}$ & $\begin{array}{l}\text { An educational program established in China by a host Chinese } \mathrm{HEI} / \text { provider } \\
\text { and a foreign partner } \mathrm{HEI} / \text { provider in cooperation. This cooprative program is } \\
\text { affliated with the host Chinese } \mathrm{HEI} / \text { provider. It operates mainly in two-campus } \\
\text { models (e.g. } 1+3,2+2,3+1,4+0 \text { ) and confers Chinese students with } \\
\text { double/joint degrees if the program is at the undergraduate or above level. } \\
\text { There are currently } 1,052 \text { degree-awarding Chinese-foreign cooperation } \\
\text { programs, such as the Bachelor's Program of Science in Accounting jointly run } \\
\text { by Wenzhou University, China, and Kean University, USA. }\end{array}$ \\
\hline
\end{tabular}

Source. Adapted from Mok and Han (2016a, p.378) and the MOE's Supervision Workstation (http: www.crs.jsj.edu.cn) Note. TNE = transnational education; CFCRS = Chinese-Foreign Cooperation in Running Schools; $\mathrm{HEI}$ = higher education institution

The Interim Provisions and the Regulations were initially introduced to guide the establishment of CFCRS institutions, or in Chinese pin yin 'zhongwai hezuo banxue jigou'. According to these two official documents, CFCRS institutions can operate with corporate capacity or legal person status (i.e. Chinese-foreign cooperation universities), or without legal person status and thus must be affiliated to the Chinese HEI (i.e. Chinese-foreign cooperation second-tier colleges). The guidance on the establishment of CFCRS programs (i.e. Chinese-foreign cooperation programs), or in Chinese pin yin 'zhongwai hezuo banxue xiangmu', was not specified until the MOE (2004) issued the Implementation Measures. In the Implementation Measures, Chinese-foreign cooperation programs are defined as "Chinese education institutions and foreign education institutions cooperate not in the form of establishing educational institutions, but cooperate in the areas of disciplines, specializations and curriculum within the territory of China to provide education programs mainly to Chinese citizens" (MOE, 2004, Article 2). 
In terms of the delivery model, the majority of Chinese-foreign cooperation programs operate with a two-campus model, or in Chinese pin yin, 'shuangxiaoyuan moshi', conferring double degrees (i.e. one Chinese degree and one foreign degree) or a joint degree. The four most popular delivery models for four-year undergraduate TNE programs in China are $1+3,2+2,3+1$, and $4+0$ (Huang, 2008). These models mean that students first study for a certain period of time (e.g. one year) in China and then complete their study at the foreign partner $\mathrm{HEl} /$ provider for the remaining time (e.g. three years) of the program. When it comes to Chinese-foreign cooperation universities and second-tier colleges, their programs also confer double degrees or a joint degree but the programs are delivered mainly in China (i.e. one-campus model). Students in these programs still have opportunities to study for a short period of time at the foreign partner HEl/provider. Regardless of the delivery model, according to the Implementation Measures, TNE in China involves substantial collaboration between Chinese and foreign partner HEls. This collaboration requires the foreign $\mathrm{HEI} / \mathrm{provider}$ to undertake at least one third of the teaching (i.e. the so-called 'Four One Third Rules') in the Chinese HEI. These three different types of TNE operations in China have important implications when considering how to apply Knight's (2016) framework in host countries.

\section{TNE in China: Towards a common framework}

Knight (2016) indicates that all TNE activities involve a foreign sending HEl/provider that offers education in a host country either independently or in collaboration with a local HEI. The role of the foreign sending $\mathrm{HEl} /$ provider and its relationship with the host country represents a fundamental criterion for defining and differentiating different types of TNE activities. This criterion is useful when Knight's framework is considered in the context of TNE in China.

First, China's limited commitments to the GATS means that foreign HEls/providers are not permitted to physically provide education services independently through the establishment of offshore campuses and programs in China unless they partner with local Chinese HEls. This relationship between foreign HEIs/providers and the host country China requires that TNE in China must be collaborative. To use the terminology of Knight's (2016) framework, TNE in China equates to 'collaborative TNE provision' (as shown in Table 1). This means that the 'independent (foreign) TNE provision' of Knight's framework that comprises three modes - branch campus, franchise university and distance education - will not apply to TNE in China. 
Second, since TNE in China does not fit in the 'independent (foreign) TNE provision' of Knight's (2016) framework, what needs to be considered is where TNE in China relates to the 'collaborative TNE provision'. TNE in China entails three types of operations (Table 2): Chinese-foreign cooperation universities, Chinese-foreign cooperation second-tier colleges, and Chinese-foreign cooperation programs. Most TNE in China confers students with double degrees or a joint degree depending on the specific agreement between Chinese and foreign HEls/providers. Compared to the four modes under Knight's 'collaborative TNE provision', it is evident that only two modes correlate with TNE in China. These are 'joint/double/multiple degree programs' and 'cofounded/developed universities'. Joint/double/multiple degree programs are compatible with Chinese-foreign cooperation programs because the program curriculum is jointly designed, delivered and monitored by local and foreign partners. Cofounded/developed universities are compatible with Chinese-foreign cooperation universities because their academic programs are mostly delivered through joint/double degree arrangements.

Two challenges therefore arise in applying Knight's framework to TNE in China. First, the framework does not appear to accommodate Chinese-foreign cooperation second-tier colleges. Thus, if the framework is used to gather data about TNE in China, it is highly likely that these colleges will be overlooked or even excluded from the scope of data collection. Data collected using the framework would thus not be able to represent a complete picture of TNE in China. In turn this would impede the process of developing a globally agreed TNE framework to collect comparable and reliable data within and across countries.

The second challenge, and perhaps a subtler one, resides in possible different understandings of branch campuses and co-founded/developed universities in research and practice. This ambiguity results from different perspectives that prevail in how TNE is viewed. One way to illustrate this ambiguity is to look at how the same TNE activity in China is described and categorized in Western and Chinese literature. For example, Ningbo Nottingham University is viewed as a 'Chinese-foreign cooperation university' in China or a 'co-founded/developed university' in Knight's (2016) framework. However, this university is often labelled as a 'branch campus' by Western scholars and practitioners with a sending country's perspective. The Branch Campus Listing produced by the Cross-Border Education Research Team (C-BERT) (2016) is one example. According to C-BERT's latest update, Chinese-foreign cooperation universities (e.g. Ningbo Nottingham University) and even Chinese-foreign cooperation second-tier colleges (e.g. Sydney Institute of Languages and 
Commerce at Shanghai University) are included in the list as 'branch campuses'. This means that even with the guidance of Knight's proposed common TNE framework, the same set of data (e.g. student enrolment) collected from Ningbo Nottingham University can be viewed by scholars and practitioners as data for different TNE modes in research and practice. These different understandings of TNE in China will likely produce inconsistent and incompatible data collection and analysis within and among sending and host countries.

\section{Discussion and conclusion}

To probe the utility of Knight's (2016) framework for host countries, this article used the literature and relevant documents to examine TNE activities in China. The article responded to the question: What should be considered when applying Knight's common TNE framework in host countries? The article discussed the need for a common TNE framework, why taking a host country's perspective matters, and the characteristics of TNE in China. Based on the ensuing discussion, the authors investigated the relationship between TNE in China and the framework. This investigation revealed two significant challenges in applying Knight's framework in the context of particular host countries such as China.

The first challenge is that Knight's framework is more applicable to sending countries than host countries like China. This is because its terms and definitions are more commonly used by sending than host countries. Host countries prefer using their own terminologies. For example, in China, the local term Chinese-Foreign Cooperation in Running Schools (CFCRS) is used by host stakeholders (e.g. Chinese governments, HEls and scholars) to denote officially approved TNE programs and institutions. Such preferences in terminology will likely breed conceptual resistance among host stakeholders and thus compromise the utility of Knight's framework. Consequently, data about TNE in China collected by host country stakeholders may be vastly different from that collected by sending country stakeholders. This increases the potential for research about TNE in China to present distinct or even contradictory pictures. If a similar situation occurs in other host countries, the prospect of developing a robust flexible common TNE framework as proposed by Knight (2016) would be further challenged.

The second challenge is that even with a common set of TNE modes/terms and definitions, in actual research and practice, host countries like China and their partner sending countries may still categorize one 
single TNE operation into different modes. As noted earlier, Ningbo Nottingham University in China has been viewed as a 'branch campus' (i.e. sending country perspective) but can also be viewed as a 'co-founded/developed university' (i.e. host country perspective). However, in Knight's (2016) framework, 'branch campus' and 'co-founded/developed university' modes are mutually exclusive. Scholars and data collectors with a host country's perspective are more likely to be aware of the cooperative nature of TNE in China and less likely to label Ningbo Nottingham University as a 'branch campus'. This could produce a situation where the peculiarities of a host country like China are neglected, misunderstood, and even taken for granted by researchers and data collectors with a sending country's perspective. The ambiguity in perceptions that can possibly result is illustrated by McNamara et al. (2013) who, when examining the impact of TNE on participating countries such as China, commented that: "it is not clear what exactly the difference is between a cooperative program and a cooperative institution" (p.64).

Given these two challenges, the development of a common framework as "a precursor to developing an international protocol for worldwide collection of TNE data" (Knight, 2016, p.34) still needs more work. For Knight's framework to be adopted globally, there would need to be agreement on the TNE terms and definitions used. As well, even with such agreement, data collection and analysis would need to occur in consistent and comparable ways. Therefore, scholars, practitioners, and public policy makers who may choose to use Knight's framework, need to consider: a) the ways in which the terms and definitions are common to sending and host countries; and b) the ways that TNE data collection and analysis can be made more consistent and comparable. Without these considerations, using Knight's framework carries risks. As shown in this article, taking the perspective of a host country such as China to better understand the peculiarities involved is one way to mitigate such risks. Nevertheless, this approach represents a positive first step toward a common TNE framework and ultimately the development of an international protocol for worldwide data collection. 


\section{References}

Altbach, P. G., and Knight, J. (2007) 'The internationalization of higher education: Motivations and realities', Journal of Studies in International Education 11(3/4), 290-305.

Bellini, N., Pasquinelli, C., Rovai, S., and Tani, S. (2016) 'The local embeddedness of foreign camppuses: The case of Tongji University in Florence', Journal of Studies in International Education 20(4), 371-385.

Cai, Y. (2011) 'Cross-border higher education in China and its implications for Finland', in Y. Cai and J. Kivistö (Eds.), Higher education reforms in Finland and China: Experiences and challenges in post-massification era, pp. 245-260, Tampere: Tampere University Press.

Cai, Y., Hölttä, S., and Lindholm, N. (2013) 'Establishing sub-campuses in China: A Finnish perspective', Journal of Research in International Education 12(2), 142-154.

China Education Daily. (2016) 'Zhangkai shuangyi, zhongguo jiaoyu geng zixin (Open wings, China's education has become more confident)', http://www.jyb.cn/china/gnxw/201603/t20160315_655067.html

Cross-Border Education Research Team (C-BERT). (2016) 'Quick facts', http://www.globalhighered.org

Fang, W. (2012) 'The development of transnational higher education in China: A comparative study of research universities and teaching universities', Journal of Studies in International Education 16(1), 5-23.

He, L. (2016) 'Transnational higher education institutions in China: A comparision of policy orientation and reality', Journal of Studies in International Education 20(1), 79-95.

HEGlobal. (2016) The scale and scope of UK higher education transnational education, London: UK HE International Unit.

Huang, F. (2007) 'Internationalisation of Higher Education in the Era of Globalisation: what have been its implications in China and Japan?', Higher Education Management and Policy 19(1), 1-15.

Huang, F. (2008) 'Regulation and practice of transnational higher education in China', in L. Dunn and M. Wallace (Eds.), Teaching in transnational higher education: Enhancing learning for offshore international students, pp. 23-33, London: Routledge.

Knight, J. (2014) 'International education hubs: Collaboration for competitiveness and sustainability', New Directions for Higher Education (168), 83-96. 
Knight, J. (2016) 'Transnational education remodeled: Toward a common TNE framework and definitions', Journal of Studies in International Education 20(1), 34-47.

Knight, J., and McNamara, J. (2015) Transnational education data collection systems: Awareness, analysis, action, London: British Council and German Academic Exchange Service (DADD).

McNamara, J., Knight, J., and Fernandez-Chung, R. M. (2013) The shape of things to come 2: The evolution of transnational education: Data, definitions, opportunities and impacts analysis, Manchester: The British Council.

Merriam-Webster's Dictionary and Thesaurus (revised and updated ed.). (2014) Springfield, MA: Merriam-Webster Inc.

MOE. (2003) 'Jiaqiang jiaoyu shewai huodong guanli, shiying woguo jiaru WTO xingshi, jiaoyubu jueding zengshe jiaoyu shewai zhuanmen jianguan jigou (To enhance the regulations on education involved in foreign actitivities and adapt to new situations after China joining the WTO, the Ministy of Education has decided to establish a special division to supervise education invovled in foreign activities)', http://www.moe.gov.cn/jyb_xwfb/xw_zllssj/moe_183/tnull_2016.html

MOE. (2004) 'Zhonghua renmin gongheguo zhongwai hezuo banxue tiaoli shishi banfa ( Implementation Meansures for the People's Republic of China Regulations on Chinese-Foreign Cooperation in Running Schools', http://www.moe.gov.cn/srcsite/A02/s5911/moe_621/200406/t20040602_180471.html

MOE. (2014) 'Jingwai banxue de xianzhuang ruhe (What is the current situation of China's TNE operations overseas)?', http://www.jsj.edu.cn/news/1/388.shtml

MOE. (2015) 'Jiaoyubu guanyu feizhi he xiugai bufen guizhang de jueding (The Ministry of Education's decisions on anulling and amending some regulations)', http://www.jsj.edu.cn/n2/1/1006/710.shtml

MOE. (2016) 'Nuli fazhan juyou zhongguo tese shijie shuiping de xiandai jiaoyu (Striving to develop world-class modern education with Chinese characteristics)', http://www.moe.gov.cn/jyb_xwfb/s5147/201604/t20160421_239406.html

Mok, K. H., and Han, X. (2016a). 'From 'brain drain' to 'brain bridging': Transnational higher education development and graduate employment in China', Journal of Higher Education Policy and Management 38(3), 369-389. 
Mok, K. H., and Han, X. (2016b) 'The rise of transnational higher education and changing educational governance in China', International Journal of Comparative Education and Development 18(1), $19-39$.

Momii, K. (2002) 'Current Commitments under the GATS in Educational Services', paper prepared for OECD/US Forum on Trade in Educational Services, Washington, D.C.: OECD/CERI.

Oxford Dictionary of English (3rd ed.). (2010) New York, NY: Oxford University Press.

Rumbley, L. E., Altbach, P. G., and Reisberg, L. (2012) 'Internationalisation within the higher education context', in D. K. Deardorff, H. de Wit, J. D. Heyl, and T. Adams (Eds.), The SAGE handbook of international higher education, pp. 3-26, Thousand Oak, CA: SAGE Publications

State Council of China. (2003) 'Regulations of the People's Republic of China on Chinese-Foreign Cooperation in Running Schools', http://www.jsj.edu.cn/n2/1/1002/51.shtml

Wang, J. (2005) Kuaguo gaodeng jiaoyu yu zhongwai hezuo banxue (Cross-border higher education and Chinese-Foreign Cooperation in Running Schools), Jinan: Shandong Education Press.

Wilkins, S. and Huisman, J. (2012) 'The international branch campus as transnational strategy in higher education', Higher Education 64 (5), 627-645.

Wilkins, S., and Urbanovič, J. (2014) 'English as the lingua franca in transnational higher education: Motives and prospects of institutions that teach in languages other than English', Journal of Studies in International Education 18(5), 405-425.

Yang, R. (2008) 'Transnational higher education in China: Context, characteristics and concerns', Australian Journal of Education 52(3), 272-286.

Zha, Q. (2012) 'Transnational higher education in China: Towards a critical culturalist research agenda', in Q. Zha and K. Mundy (Eds.), Education and global cultural dialogue: A tribute to Ruth Hayhoe, pp. 107-123, New York, NY: Palgrave Macmillan. 